\title{
A Coleção Mochica do Museu de Arqueologia e Etnologia da USP: testemunhos materiais da cosmovisão andina
}

Cássia R. Bars *

BARS, C.R. A Coleção Mochica do Museu de Arqueologia e Etnologia da USP: testemunhos materiais da cosmovisão andina. Revista do Museu de Arqueologia e Etnologia, São Paulo, 20: 345-359, 2010.

Resumo: $O$ objetivo deste artigo é discutir preceitos atribuidos à cosmovisão andina por meio de análises iconográficas baseadas em artefatos pertencentes à coleção mochica do Museu de Arqueologia e Etnologia da USP. É também demonstrado como a semiótica, aplicada à arqueologia, torna-se uma excelente ferramenta metodológica para análises envolvendo artefatos que servem como suporte para iconografias complexas.

Palavras-chave: Cosmovisão andina - Iconografia mochica - Semiótica em arqueologia.

$\mathrm{O}$ acervo de objetos pré-colombianos do Museu de Arqueologia e Etnologia da USP ${ }^{1}$ é composto por 725 peças. Destas, 38 estão catalogadas como "mochicas". Para a realização deste trabalho, foram selecionados nove artefatos considerados de grande relevância para o estudo de aspectos ligados à cosmovisão andina.

Segundo Vera Penteado Coelho, grande parte desta coleção, proveniente de diferentes fontes ${ }^{2}$ teria sido adquirida através de contatos com huaqueros (mercadores ilegais de antiguidades) (Coelho 1977). É necessário notar, entretanto, que apesar das dificuldades existentes no

(*) Doutoranda do Programa de Pós-Graduação em Arqueologia do Museu de Arqueologia e Etnologia da Universidade de São Paulo. <cassiabars@usp.br> (1) A partir deste momento, o Museu de Arqueologia e Etnologia da USP será referenciado como MAE, sigla pela qual a instituição é comumente conhecida. estudo de uma coleção como esta, é sabido que a cultura material escolhida para análise é composta, na sua grande maioria, por objetos de prestígio e de caráter ritualístico, e que estes podem ser encontrados principalmente em contextos funerários (Lavalée 1970; Bourget 1994). Esta constatação é reforçada pelos resultados obtidos em inúmeras escavações atuais, como as dos sitios de Sipán e de Ventarrón, sob a responsabilidade do arqueólogo Walter Alva, o qual sustenta também esta afirmação (Walter Alva, comunicação pessoal). A própria ação dos huaqueros locais é, até hoje, voltada para a descoberta de tumbas intactas, principais alvos dos saques. Estes saques obedecem a uma

(2) A coleção de artefatos pré-colombianos do MAE é composta por 183 peças provenientes da coleção do Museu Paulista, 43 da Coleção Plíneo Ayrosa, 343 da Coleção Max Uhle e 156 da coleção do Antigo MAE. 
mesma "técnica", que é passada de geração a geração, facilmente reconhecida pelos padrões de distúrbio deixados nos sítios arqueológicos.

A escolha dos nove artefatos para análise neste artigo na realidade é reflexo de uma necessidade percebida no decorrer da execução da dissertação de mestrado O Felino na Iconografia Mochica: Análise dos Padrões de Estilização na Cerâmica Ritual (Bars 2010), na qual mais de 1417 artefatos mochicas pertencentes ao Museu Arqueológico Rafael Larco Herrera, ${ }^{3}$ em conjunto com 25 peças mochicas pertencentes ao MAE, foram analisadas. ${ }^{4}$ Apesar de a coleção mochica do MAE ser numericamente bastante inferior à coleção do Museu Larco, foi observado que a riquíssima iconografia presente em alguns de seus exemplares traduzia uma verdadeira "sintese" da cosmovisão andina, muito pouco explorada pelos pesquisadores da área. Devemos também ressaltar que pouquissimas publicações foram feitas a respeito desta coleção, com destaque para os trabalhos de Vera Coelho (1977) e de Márcia Arcuri (2009).

As análises realizadas na dissertação de mestrado mencionada priorizaram o estudo de imagens relacionadas a mamiferos predadores, representados na iconografia mochica. Neste artigo, que busca ressaltar a importância e a relevância da coleção mochica do MAE, o enfoque das análises recairá sobre questões mais abrangentes, relacionadas à cosmovisão andina como um todo. A análise das peças escolhidas reflete com clareza e por si só o porquê de sua escolha dentre os artefatos mochicas pertencentes à coleção do Museu, como será exposto mais a frente no texto.

Grande parte destes artefatos apresenta uma iconografia de caráter "supranatural". ${ }^{5}$

(3) A partir deste momento, o Museu Arqueologico Rafael Larco Herrera será referenciado como Museu Larco, nome pelo qual é normalmente conhecido.

(4) Dentre as 725 peças da coleção de artefatos précolombianos do MAE, 38 estão catalogadas como

"mochicas". Destas, 25 possuiam caracteristicas pertinentes para o estudo proposto pela dissertação citada.

(5) Neste trabalho serão utilizadas as expressões "mundo supranatural" e "universo supranatural" como referências às forças imateriais e simbólicas que regem o funcionamento do universo dentro dos preceitos ditados pela cosmovisão andina.
Sendo assim, partindo da premissa de que sua proveniência está relacionada a contextos rituais e/ou funerários, será realizado um estudo pautado nos mecanismos sobre os quais as crenças neste mundo supranatural se apóiam, ou seja, sobre as bases da cosmovisão andina.

A cultura mochica (também conhecida como "moche") se desenvolveu na costa norte peruana durante o chamado Periodo Médio (aproximadamente entre 100 a.C. e 800 d.C.). Inserida nesta grande área cultural conhecida como "Andes", compartilhou com muitos povos certos "conceitos fundamentais" que permeavam seus modos de organização social e política, além de aspectos filosóficos, como a compreensão dos mecanismos que regeriam o funcionamento do universo natural e supranatural. Em outras palavras, compartilhavam, em termos gerais, de uma mesma cosmovisão.

Segundo Johanna Broda, o conceito de cosmovisão pode ser definido como a estrutura sobre a qual os membros de uma sociedade combinam, de maneira coerente segundo suas crenças, suas noções e relações com o meio ambiente fisico, com os seres viventes da natureza, com o mundo supranatural, e todas as "regras" às quais estes elementos estão sujeitos (Broda 2001: 16-17).

A maioria dos pesquisadores empenhados em compreender tais mecanismos de funcionamento e de permanência desta "cosmovisão andina" admitem, em maior ou menor grau, a continuidade e a transmissão de certos conceitos simbólicos ao longo do tempo, compartilhados por diversas culturas (Lavalée 1970; Moseley 1992; Lemos 1998; Golte 2004, 2005, 2006; Hurtado Rodriguez 2006). Esses conceitos fundamentais compartilhados referem-se a concepções a respeito do funcionamento da natureza e do universo como um todo, e da dinâmica dos movimentos cíclicos e lineares que os permeiam.

\section{Aspectos teórico-metodológicos da análise proposta}

Na busca de uma maior objetividade, foi utilizada uma metodologia baseada na semiótica, 
hoje comumente e amplamente utilizada em análises iconográficas ligadas a artefatos e estruturas arqueológicas (Preucel 2006). No caso dos estudos relativos à área andina, os conhecimentos acerca da cosmovisão destes povos são aliados ao método semiótico, propiciando uma melhor compreensão dos contextos de construção das imagens. ${ }^{6}$

A semiótica constitui um campo de pesquisa que envolve diversas posturas teóricas e ferramentas metodológicas. Os objetos de estudo da semiótica, os signos, podem tomar a forma de palavras, imagens, sons, gestos e objetos. Para os principais teóricos da semiótica, Ferdinand de Saussure e Charles Peirce, ${ }^{7}$ ela deveria ser considerada uma ciência. (Saussure 1974.; Peirce, in Hartshorne e Weiss 1931). Saussure associava a semiótica às teorias estruturalistas de Lévi-Strauss. De modo análogo ao autor, que busca descrever e compreender a organização e formação dos mitos, dos sistemas de parentesco e do totemismo, os semioticistas deveriam buscar descrever a organização dos sistemas de signos.

É comum a muitos pesquisadores, ao analisar os conceitos simbólicos relacionados ao mundo andino, trabalhar com a idéia de "pares de opostos" (presente nos estudos fundamentados pela teoria estrutural de LéviStrauss, e base das oposições binárias de Saussure). Estas idéias se tornaram muito atraentes aos arqueólogos e estudiosos da área, pois pareciam se encaixar perfeitamente a diversos conceitos "pares" presentes na mentalidade andina, como hanan/hurin e wañuy/ kawsay, ${ }^{8}$ e a gama de significados aparentemente "contrários" associados a eles.

(6) Dentre os autores que utilizaram esta metodologia em seus trabalhos, podemos citar Donnan 1976, Donnan e McClealland 1979, Bourget 1994 e Golte 2006.

(7) O termo semiótica foi criado pelo filósofo Charles Peirce. Para ele, seria uma "doutrina formal dos signos", e possuiria um funcionamento lógico e racional (Peirce, in Hartshorne e Weiss 1931). Já para Ferdinand de Saussure, considerado o "pai da semiologia" (ou semiótica), ela seria uma ciência que estuda o papel dos signos como parte integrante da vida social (Saussure 1974).

(8) Acima/abaixo e zênite/nadir
Nos dias de hoje, entretanto, muitos estudiosos da semiótica procuram não concentrar seus estudos somente nos modelos estruturalistas, buscando, além da compreensão das estruturas internas de um dado discurso (e o relacionamento de todas as suas unidades de significação entre si), compreender também o papel dos signos em seu contexto social (Greimas 2004: 92 ; Lopes e Hernades 2005: 9). "O modelo de Saussure, por si só, não é considerado suficiente aos estudos arqueológi$\cos .$. pois tem como foco somente a análise da estruturação dos signos em si, em detrimento da prática social" (Preucel 2006: 3). No âmbito da arqueologia, o uso da semiótica como ferramenta metodológica é mais comumente encontrado em estudos que seguem as linhas pós-processuais ou a arqueologia cognitiva. ${ }^{9}$ Tais linhas de pensamento favorecem a compreensão dos signos sob um ponto de vista de "sistemas simbólicos", e as metodologias da semiótica são apontadas para o estudo da formação e da compreensão dos "significados" dentro de um contexto e como seus mecanismos de funcionamento proporcionam a manutenção e a construção de padrões sociais. Sendo utilizada desta forma, a semiótica tornase uma forte aliada dos estudos iconográficos em arqueologia.

Hodder, por exemplo, critica o uso da análise semiótica em arqueologia quando realizada de modo a seguir estritamente as proposições de Saussure, principalmente quando as análises se referem a analogias com estudos lingüisticos. Ele reconhece, entretanto, o valor dos estudos semióticos para a área, $\mathrm{e}$ propõe uma utilização mais consciente da metodologia em seu trabalho A Arqueologia dos Significados Contextuais (1987). Segundo o autor, "a arqueologia como disciplina particularmente dedicada à leitura da cultura material, precisa estar envolvida no debate sobre a análise semiótica" (Hodder 1987: 3).

(9) Entre eles, Hodder 1987, Chase e Dibble 1987, Chase 1991, Wynn 1993, Noble e Davidson 1996, Bouissac 2003 e Preucel 2006. 
As teorias pós-estruturalistas estão intimamente relacionadas com o contexto pósmoderno que deu origem às linhas pósprocessuais e, posteriormente, à arqueologia cognitiva. De acordo com Preucel, independentemente dos rótulos dados às diversas linhas consideradas pós-estruturalistas (entre elas o marxismo antropológico, o estrutural-marxismo e o interacionismo), todas elas partem de um relacionamento intimo e crítico com o estruturalismo e, de forma geral, têm a tendência de rejeitar abordagens deterministas e agregar conceitos como subjetividade, discurso, gênero e identidade (Preucel 2006: 122). Manfred Frank (1989) propôs o termo "neo-estruturalismo" para enfatizar a evidente "continuidade" da teoria estruturalista nos preceitos ditados pelas diversas linhas pós-estruturalistas. Já Richard Harland $(1987,1993)$ sugere o termo "superestruturalismo" para linhas de pensamento que englobam preceitos estruturalistas, pós-estruturalistas, o estrutural-marxismo, a teoria lacaniana, os estudos culturais de Foucault e a própria semiótica (Preucel 2006: 122).

É proposta em nossas análises a adoção do perspectivismo de Viveiros de Castro (Viveiros de Castro 2002) como base teórica, a fim de aplicar a metodologia da semiótica de modo mais amplo e adequado às análises iconográficas do universo pictórico mochica. O perspectivismo está intimamente ligado ao estruturalismo de Lévi-Strauss, porém sustenta um enfoque voltado para uma visão um pouco diferenciada sobre a questão dos "pares de opostos". ${ }^{10}$ Segundo Viveiros de Castro, a mentalidade ameríndia não compreende o mundo por meio de estruturas rigidas. Isto equivale dizer que o universo, em termos de funcionamento e de valores, obedece a certos conjuntos de regras, ditadas geralmente pelos preceitos da cosmovisão adotada. A estas regras estariam submetidos todos os seres. Entretanto, estes seres não estão classificados de uma forma fixa, dentro de uma estrutura imutável - animal em contraposição a humano; mortos em contraposição aos vivos;

(10) "Sou um estruturalista, como todo bom antropólogo" (Viveiros de Castro 2002: 485). homens em contraposição a mulheres. Segundo o perspectivismo, os diversos seres que habitam o universo, supranaturais ou não, o apreendem de acordo com pontos de vista distintos. Os homens vêem a eles si próprios como humanos, os animais como animais, e os seres supranaturais como supranaturais. Entretanto, para os animais predadores, o homem é o animal de presa. Aos olhos do animal, ele próprio é o humano. O animal teria sua própria cultura, sua própria organização social e hábitos. Sendo assim, todos os seres do cosmos possuiriam uma perspectiva sobre o valor e o significado das coisas e, desta forma, não haveria espaço para uma única estrutura de pares de opostos de "conceitos fixos". "O sangue é a cerveja do jaguar" - o sangue, um elemento "natural", torna-se aos olhos do jaguar, um produto "civilizado". "E assim o que chamam de 'natureza', pode bem ser a 'cultura' dos outros" (Viveiros de Castro 2002: 361)

Esta visão não considera necessariamente os estudos que seguem uma metodologia que trata os pares de opostos, ou a questão da "dualidade", de uma forma um pouco mais rigida, como totalmente inadequados ${ }^{11}$ (Bars 2010: 29). O próprio Viveiros de Castro se perguntou: "O que fazer com as abundantes indicações a respeito da centralidade dessa oposição nas cosmologias sul-americanas?" (Viveiros de Castro 2002: 368). E, em resposta à sua própria pergunta, o autor conclui, ao analisar a questão do xamanismo entre os yawalapiti, que "as noções de metamorfose e, sobretudo, a de apapalutápa, são muito complexas; ... sua importância no pensamento indigena , parece-me, mais uma vez, colocar em questão a pertinência, ou pelo menos a suficiência, da grande dualidade entre Natureza e Cultura. (...) Nas Mitológicas [citando Lévi-Strauss], essa dualidade aparece como organizadora de todo o pensamento ameríndio; ela deixa escapar, entretanto, ou não lhe dá todo o espaço que merece, a um terceiro domínio ontológico, que chamamos, na falta de um termo melhor, de 
Sobrenatureza. (...) do ponto de vista dos espíritos, humanos e animais comungam aspectos essenciais; do ponto de vista dos animais, humanos e espíritos quiçá sejam a mesma coisa. Há portanto, talvez, dualidade; mas ela seria apenas a redução de uma estrutura mais rica" (Viveiros de Castro 2002: 85). "A distinção natureza/cultura deve ser criticada, mas não para concluir que tal coisa não existe" (Viveiros de Castro 2002: 349).

Jürgen Golte, renomado pesquisador da iconografia mochica, dá aos "pares de opostos" um grande peso em suas análises. Tais opostos complementariam um ao outro e, se encontrando em tinku, dariam origem a novas situações, como nascimentos e mortes (Golte 2004: 126, 2006: 766). Entretanto, ao mesmo tempo em que trabalha com esta noção, Golte geralmente acaba por concluir a inconsistência da tentativa de aplicar o conceito dos pares de opostos de forma rigida, afirmando que estes existem, mas não podem ser considerados como conceitos fixos. Sobre o par de "significados fixos" feminino/masculino, Golte escreveu: "Cada metade complementar, por sua vez, é subdividida novamente em duas sub-partes femininas e masculinas" (Golte 2004: 144). Ou, com menor grau de rigidez: "O mundo oculto, mesmo que predominantemente feminino, integrava uma parte masculina" (Golte 2004: 172).

Os "pares de opostos" devem, portanto, ser compreendidos como mecanismos de funcionamento estrutural, e não como conceitos fechados ligados aos significados das coisas. Cada "significado" dependeria do ponto de vista adotado. Assim como afirmam Renfrew e Bahn (1991: 391), é possivel compreender como os simbolos se relacionam entre si e seus mecanismos de funcionamento, mas talvez a compreensão seus "significados" por completo esteja além de nosso alcance. No caso andino, esses significados são múltiplos; podendo ser compreendidos através de diversas perspectivas, de acordo com o contexto em que estão inseridos, exigindo uma aplicação mais consciente dos métodos semióticos.

A base do método semiótico aplicado consiste na análise do "todo" que compõe uma dada imagem e de suas respectivas unidades mínimas de significação. Estas unidades mínimas, ou sememas, são elementos gráficos que por si só possuem significado, mas que, em conjunto com outros elementos, podem vir a formar novos significados. As combinações dos sememas fornecem informações de como a imagem deve ser "lida" e de seus "sentidos de leitura" (Oliveira 2004: 122). Há uma "coerência" que deve conectar as imagens estudadas, no sentido de que uma afirmação feita para uma destas imagens, parte delas ou conjunto delas, deva se sustentar e se repetir em outras situações semelhantes, dentro de um mesmo discurso pictórico (Golte 2006: 800). Há, sem dúvida, algo como o que o estudioso Golte (2006: 800) denomina de uma "regra de interpretação geral", a qual oferece uma ampla base de sustentação para análises deste tipo. Essa "regra", neste caso, seria baseada nos conceitos provenientes da cosmovisão andina como um todo. ${ }^{12}$

\section{A leitura dos artefatos}

Apesar de a coleção do MAE apresentar um pequeno número de peças mochicas, conforme comentado acima, a variedade dos temas abordados na iconografia que encontramos nestes artefatos é de grande valor para uma análise que envolva questões relacionadas à cosmovisão. Os artefatos eleitos para compor este artigo apresentam uma temática consideravelmente relevante para o estudo proposto, ligada principalmente a seres supranaturais e a sememas de forte caráter simbólico. Esses seres supranaturais constituem personagens constantes na iconografia mochica. Sua composição pictórica envolve elementos ligados a humanos, animais e, por vezes, espécies vegetais, feições geográficas ou objetos inanimados. Um dos principais conceitos incutidos nas imagens de

(12) Este é um tema amplamente debatido e referenciado na historiografia. Citamos Golte apenas como um exemplo entre muitos trabalhos que assumem esta posição, tais como Donnan 1976; Donnan e McClealland 1979; Cordy-Collins 1992; Bourget 1994, 2001, 2006, entre outros. 
seres supranaturais leva em consideração as inúmeras relações entre as diversas espécies de animais na natureza. Estas relações fariam referência não só à grande multiplicidade de seres que habitam o cosmos, mas também aos diferentes âmbitos nos quais estes podem ser encontrados. Esses âmbitos podem ser compreendidos, de uma forma mais generalista, como "aquático", "terrestre" ou "celeste", ou de forma mais especifica, como "deserto", "marinho", "montanhoso", "lacustre" etc., de acordo com os sememas que integram a composição das imagens em questão.

Dois vasos da coleção do MAE apresentam como temática um mesmo personagem, que será aqui denominado "animal da sintese"13 (Figs. 1a e 1b, 2a e 2b). A escolha do termo "animal da síntese" foi baseada na identificação dos inúmeros sememas presentes na composição das imagens que retratam este ser supranatural (Bars 2010: 174). Esses sememas apresentam uma variedade muito grande e podem ser relacionados a diferentes espécies como moluscos, peixes, mamiferos terrestres como felinos e canideos, répteis e aves. A imagem do animal da sintese traz em si a complexidade das relações entre as diferentes espécies na natureza. "Na iconografia mochica representa-se, frequentemente, a imagem de uma criatura quimérica que emerge de um caracol, (...)

(13) Em se tratando das denominações dadas aos "seres supranaturais”, pode-se dizer que não há, até o presente momento, uma nomenclatura "oficial", ou mesmo utilizada de maneira mais frequente, que seja adotada pelos pesquisadores como um todo. Isso se dá porque não existe um consenso sobre sua composição; não há concordância quanto às partes de animais que formam suas imagens. Para cada caso existem diversas denominações. Sendo assim, buscamos criar ou adotar denominações que não têm a intenção de determinar a qual animal exatamente essas imagens se referem. Essas denominações "genéricas" foram adotadas após a conclusão das análises realizadas para a dissertação de mestrado "O Felino na Iconografia Mochica: Análise dos Padrões de Estilização na Cerâmica Ritual" (Bars 2010). O resultado das análises demonstrou que é impossivel determinar que tais seres supranaturais sejam compostos por um conjunto fixo de partes de animais. Estes, na verdade, podem assumir, em suas diversas formas de manifestação, aparências de animais distintos. símbolo da origem comum e da interdependência das diferentes formas de vida" (Alva Meneses 2006: 145).

As Figuras 1a e 1b trazem a imagem de um animal da sintese composto por sememas que, de forma geral, podem ser relacionados aos ambientes aquático (representado pela concha gastrópode sobre suas costas) e terrestre (representados pelos sememas relativos à cauda e às orelhas pertencentes a um mamifero terrestre, pelas garras que lembram as de um tatu e pela língua bifida de um réptil, além de "antenas", que são as mesmas vistas em representações mochicas de caracóis de rio, animais que habitam tanto o âmbito terrestre como o aquático). Já as imagens apresentadas nas Figuras $2 \mathrm{a}$ e $2 \mathrm{~b}$ trazem um animal da sintese também composto por antenas de caracol, com corpo, cabeça e orelha de um mamifero terrestre (sendo o formato do focinho o de um canídeo), lingua bifida e concha gastrópode, além de sememas sobre o pescoço do personagem que são geralmente relacionados a penas de aves, e garras, que neste caso não são as de um animal cavador como um tatu, mas sim de uma ave de rapina. ${ }^{14}$ Enquanto o personagem nas Figuras 1a e 1b traz em si a "oposição" ou "relação" entre os âmbitos terrestre e aquático, o visto nas Figuras 2a e 2b está imbuido das relações entre os três principais âmbitos terrestre, aquático e celeste -, sendo que este último estaria representado pelos sememas ligados às aves.

Inúmeras "relações" e "oposições" estão presentes nessas imagens. Conceitos de "dualidade" (ou de "pares de opostos") são expressos por ideias como a de "maciez e dureza", simbolizadas pela presença das conchas e pelas antenas de caracol (sendo que estes dois animais possuem um corpo mole, sem ossos, e, ao mesmo tempo, a dureza da concha

(14) A análise dos sememas em questão, e a identificação de cada um deles como pertencente a uma espécie de animal em particular, foi possivel após pesquisas minuciosas realizadas para a dissertação de mestrado já mencionada (Bars 2010). Tais análises produziram tabelas de sememas que levavam em consideração tanto os padrões de estilização mochicas como a anatomia da fauna local. 


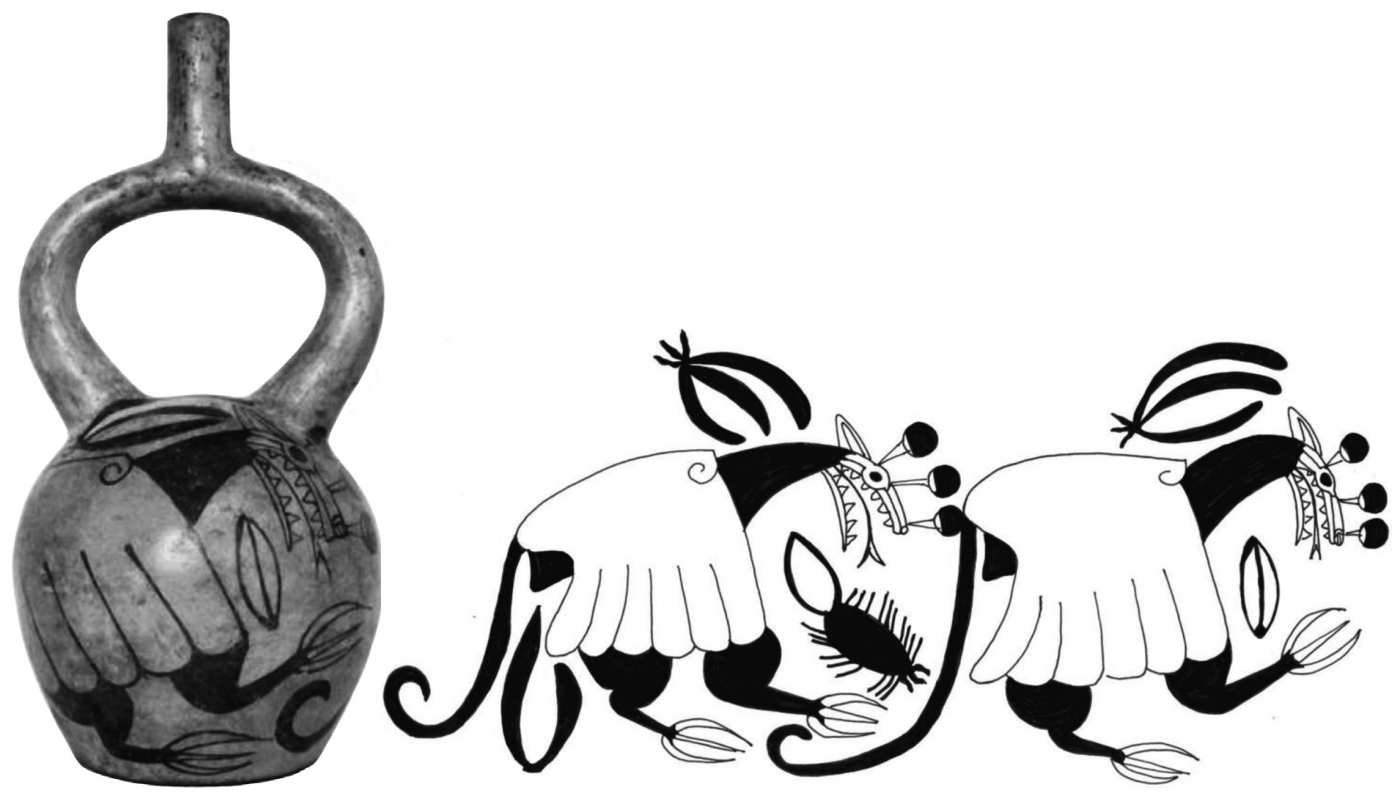

Fig. 1a. Representação de "animais da sintese". Acervo do Museu de Arqueologia e Etnologia da USP (RG 3575). Fotografia da autora.

Fig. 1b. Detalhe de personagens sobre o corpo do vaso representado na Fig. 1a. Ilustração da autora.
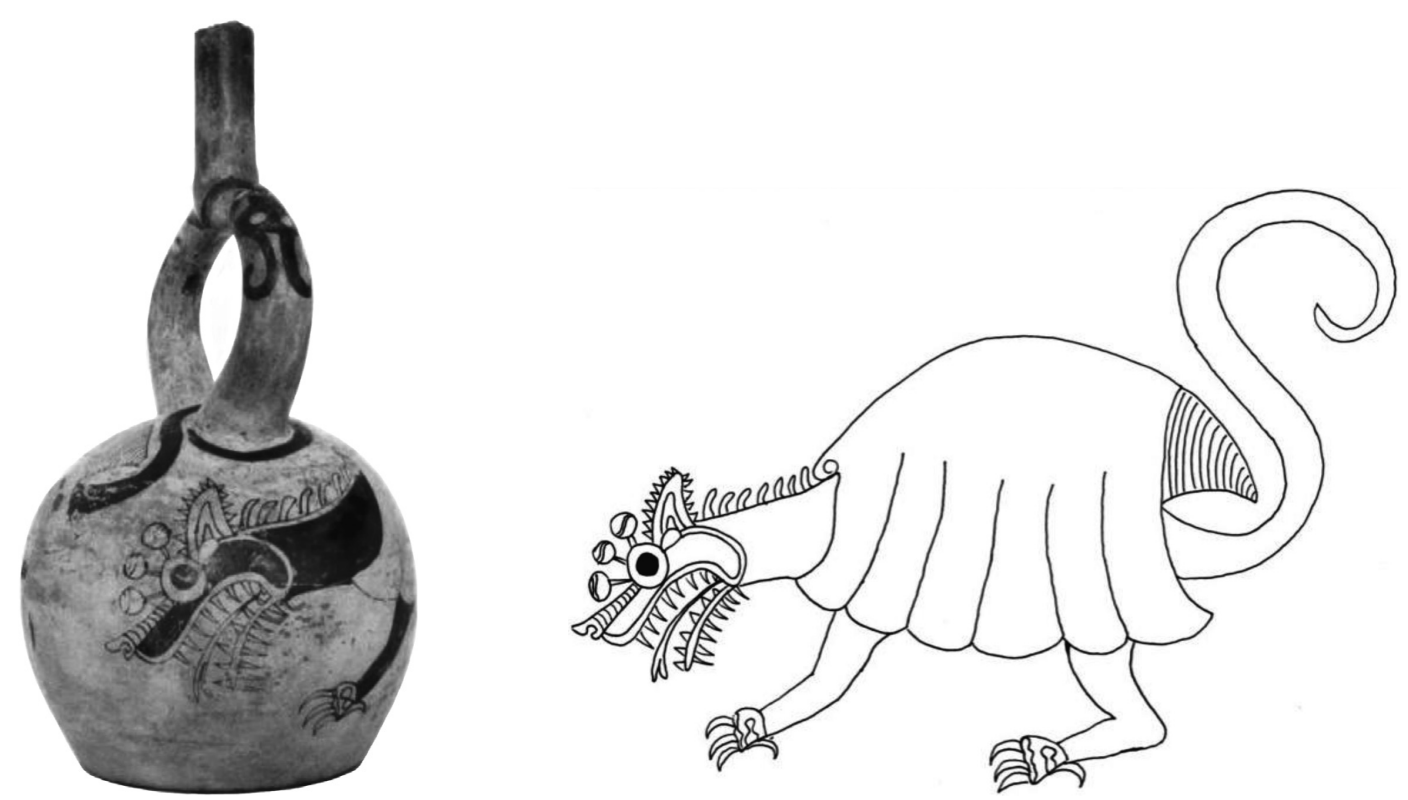

Fig. 2a. Representação de "animal da sintese". Acervo do Museu de Arqueologia e Etnologia da USP (RG 3574 ). Fotografia da autora.

Fig. 2b. Detalhe de personagens sobre o corpo do vaso representado na Fig. 2a. Ilustração da autora. 
(Alva Meneses 2006: 152). Outros "pares de opostos" podem ser identificados por meios de elementos relacionados à água e à terra; ou mais especificamente, ao deserto (simbolizado pela vegetação, melhor visualizada na Figura 1b) e ao mar (simbolizado pela concha $\left.{ }^{15}\right)$. Mas não apenas a dualidade estaria presente nestas imagens. Conforme afirma Viveiros de Castro , esta dualidade deve realmente ser compreendida como a "redução de uma estrutura mais rica". O animal da sintese é um personagem "único", "coeso" e "independente", e que, portanto, representa também conceitos ligados à "unicidade". Suas inúmeras formas de apresentação, e o fato de sua composição englobar os mais diversos âmbitos e animais, entretanto, também podem ser compreendidas como uma manifestação de "multiplicidade". A "dualidade", a "multiplicidade" e a "unicidade" são conceitos fundamentais que exprimem, de forma geral, as bases estruturais da cosmovisão andina. Esta é a principal razão pela qual a nomenclatura "animal da sintese" foi adotada.

A presença contundente destes conceitos pode também ser notada nas representações de um ser supranatural conhecido como "Ai apaec", personagem considerado por muitos pesquisadores como a "divindade superior mochica” (Kutscher 1954: Klein 1967: Lavalée 1970: Benson 1972; Lumbreras 1976; CordyCollins 1992; Bourget 1994; Larco Hoyle 2001; Golte 2005; Alva 2006; Alva Meneses 2006). O personagem assume diversas formas de manifestação e, assim como o animal da sintese, pode apresentar sememas ligados às mais diversas espécies de animais e âmbitos. Uma das formas mais comuns sob as quais Ai apaec é retratado é como um ser antropozoomorfo, com corpo humano, face humana, dentes caninos próprios de um mamifero predador e serpentes vivas atadas ao corpo (geralmente pendendo de uma espécie de cinturão e representadas como

(15) As conchas gastrópodes retratadas sobre o dorso das imagens de animais da sintese aqui em análise referem-se, por seu formato característico, às do gênero Strombus (de habitat marinho). Nas Figuras 1a e 1b é possivel observar conchas que, por seu formato arredondado nas extremidades, talvez se refiram à espécie Strombus galeatus. serpentes supranaturais com cabeça de mamifero).

São muito comuns cenas em que Ai apaec está envolvido em combates. Geralmente, estes combates representam uma "oposição" entre âmbitos distintos, como o marinho e o terrestre (indicado pelos sememas presentes nas imagens dos combatentes). Ai apaec, por sua caracteristica "múltipla", pode ser retratado com elementos ligados a qualquer um dos possiveis âmbitos. Na maioria das vezes, ele é retratado como vencedor dessas batalhas. Entretanto, algumas vezes ele aparece como perdedor, e até mesmo como "morto". Estaria contida nesta "divindade superior" tanto a derrota quanto a vitória, tanto a morte quanto a vida.

A manutenção dos mecanismos que regem o eterno ciclo de nascimentos e mortes traduz também um conceito fundamental da mentalidade andina. Enquanto que os conceitos de "unicidade", "dualidade" e "multiplicidade" fornecem a estrutura das relações entre os seres que habitam o universo, os mecanismos cíclicos e lineares mantém seu funcionamento dinâmico. Na Fig. 3, é possivel observar uma imagem tridimensional de Ai apaec em forma de "montanha". Seu corpo antropozoomorfo funde-se com a forma de uma montanha de cinco picos. A imagem da montanha de cinco picos é comumente utilizada em cenas que têm como tema o "sacrificio na montanha". Nestas cenas são retratadas vitimas que são jogadas do alto da montanha, desfalecem no chão e espalham seu sangue sobre a terra. Ai apaec é geralmente retratado como a entidade para qual este tipo de sacrifício é realizado (Arcuri 2009: 44; Bars 2010: 222).

O fato de Ai apaec estar representado como a própria montanha no artefato em questão indica sua união com o "todo" da natureza, sua caracteristica ao mesmo tempo "múltipla" e "única". Os sacrifícios provavelmente tinham como propósito assegurar tanto a fertilidade agricola como a manutenção dos ciclos vitais como um todo. Do sacrifício nascerá a vida, e este "movimento", esta "transformação", manterá o bom funcionamento do universo.

Segundo preceitos da cosmovisão andina, não existe nenhum ser, vivo ou "morto", seja 


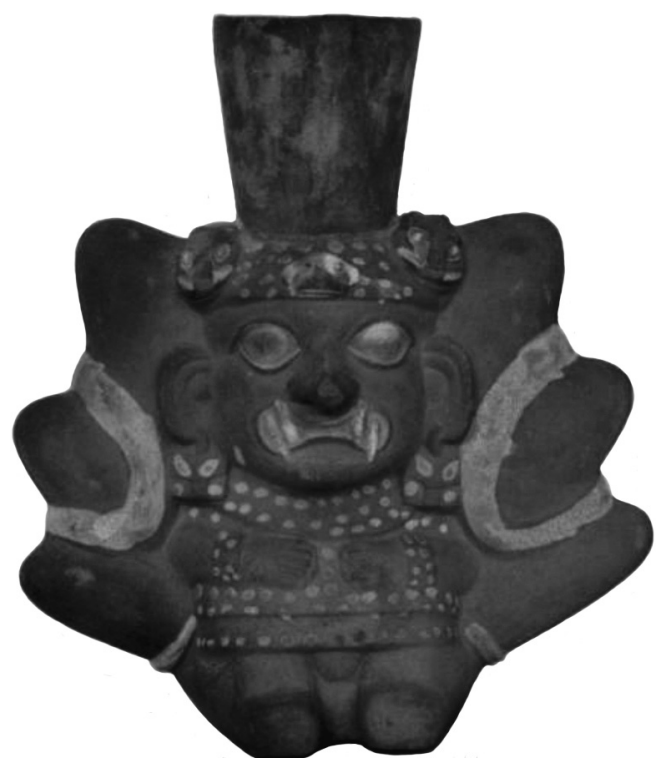

Fig. 3. Representação tridimensional de Ai apaec como "montanha". Acervo do Museu de Arqueologia e Etnologia da USP (RG 3876). Fotografia da autora.

ele um animal, ser humano, vegetal, ou mesmo um objeto ou uma feição geográfica como uma montanha, que não esteja em perpétuo movimento dinâmico de transformação. Este movimento é comumente expresso na iconografia andina através de sememas como o do "escalonado" (Fig. 4), o da "voluta" e o da "voluta escalonada" (Fig. 5). O semema denominado de escalonado exprime tanto idéias ligadas aos diferentes pisos ecológicos andinos (representando, de forma vertical, a relação entre eles - do litoral aos altos picos da cordilheira) como também a questão do sacrifício (Alva Meneses 2006: 151; Arcuri 2009: 44-46). A iconografia mochica indica que um dos seus principais rituais de sacrifício ocorria no topo de uma pirâmide escalonada. Todos os sacrifícios eram realizados sob a perspectiva de que havia um tempo linear e um tempo cíclico. $\mathrm{O}$ tempo linear indicava que uma vida havia chegado a seu fim, ao menos sob esta forma. O tempo ciclico indicava que o sangue sacrificial penetraria na terra e a fecundaria, fazendo da morte surgir a nova vida. O semema da voluta é a representação sintética do movimento imposto pelo tempo cíclico. O símbolo da voluta escalonada representa a manutenção do tempo cíclico (e por consequência também do linear) por meio dos rituais de sacrifício (Alva Meneses 2006: 151; Arcuri 2009: 44-46; Bars 2010: 235)

A imagem de Ai apaec (Fig. 3) está ligada tanto à questão do sacrifício como também à imagem do animal da sintese. Na imagem das Figuras 1a e 1b, é possivel observar um semema de formato oval, com uma linha no centro, logo abaixo do pescoço do personagem (na Figura $1 \mathrm{~b}$ ele está junto ao animal da sintese representado à direita). Esse semema representa um fruto de ulluchu. Estudos iconográficos e descobertas arqueológicas (Alva Meneses 2006:153; Wassén 1989: 42) indicam que frutos como estes eram utilizados em rituais de sacrifício. Eles seriam possivelmente misturados ao sangue da vitima, o qual seria ingerido por um dos principais participantes do ritual. Segundo Henry Wassén (1989: 42), "O ulluchu é o simbolo do sangue".

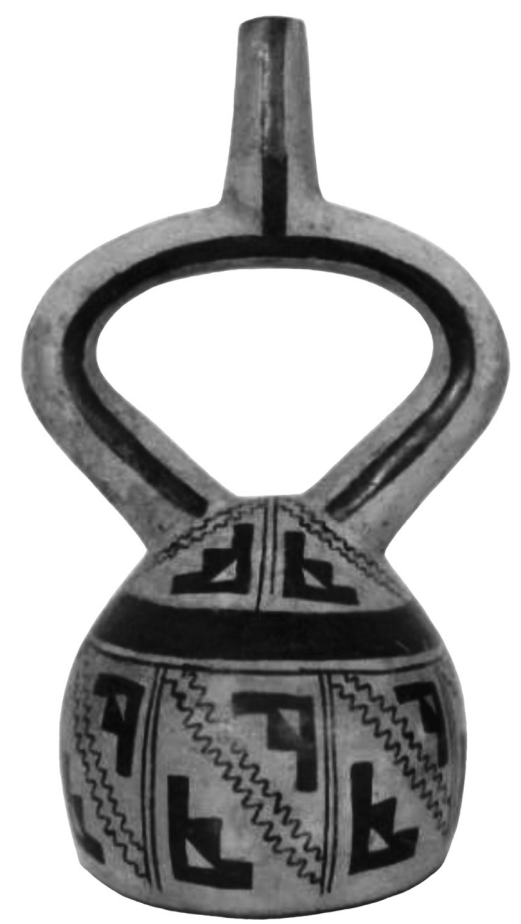

Fig. 4. Representação de sememas de "escalonados" sobre o bojo do vaso cerâmico. Acervo do Museu de Arqueologia e Etnologia da USP (RG 3579). Fotografia da autora. 


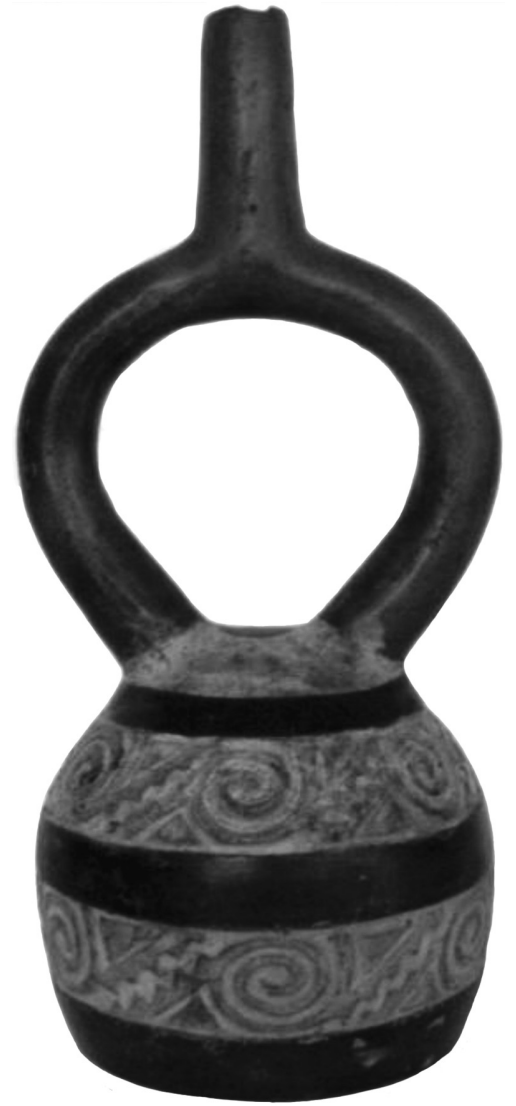

Fig. 5. Representação de sememas de "volutas escalonadas" sobre o bojo do vaso cerâmico. Acervo do Museu de Arqueologia e Etnologia da USP (RG 3583) Fotografia da autora.

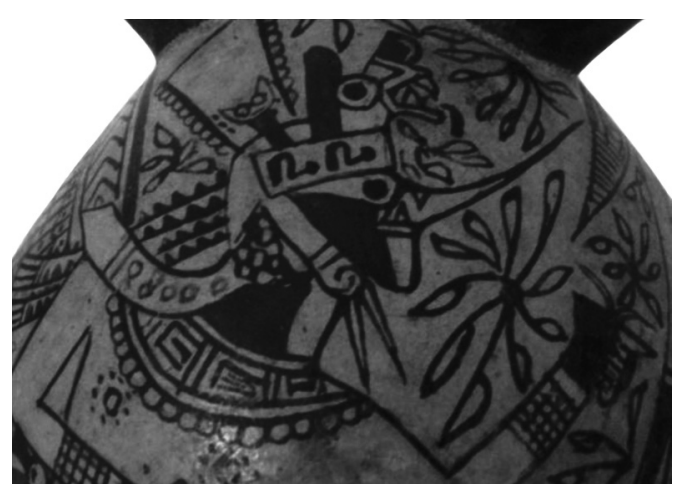

Fig. 6. Representação de "guerreiro beija-flor". Acervo do Museu de Arqueologia e Etnologia da USP (RG 3875. 6037). Fotografia da autora.

Fig. 6a. Detalhe de "guerreiro beija-flor" segurando uma bolsa com feijões. Fotografia da autora.
Personagens conhecidos como "guerreiros" ou "corredores" são geralmente retratados participando de uma série de rituais relacionados à questão do sacrifício. Duas representações de guerreiros antropozoomorfos podem ser observadas nas Figs. 6 (guerreiro beija-flor) e 7 (guerreiro ave de rapina). Nestes dois casos, os guerreiros possuem corpo humano e cabeça de ave, mas, de forma geral, existem representações de guerreiros que combinam feições humanas a diversos tipos de animais. $\mathrm{Na}$ iconografia, encontram-se representações de guerreiros nas quais estes figuram sozinhos (como é o caso dessas duas peças) ou em meio a cenas complexas, na maioria das vezes acompanhados por outros guerreiros animais diversos (Bars 2010: 193).

Pode-se dizer que estas "cenas complexas" retratam diversos eventos litúrgicos conectados entre si, tendo como ápice o sacrificio de prisioneiros. Segundo as análises iconográficas do arqueólogo Jaime Castillo, o ato do sacrifício ocorreria após uma batalha ritual.

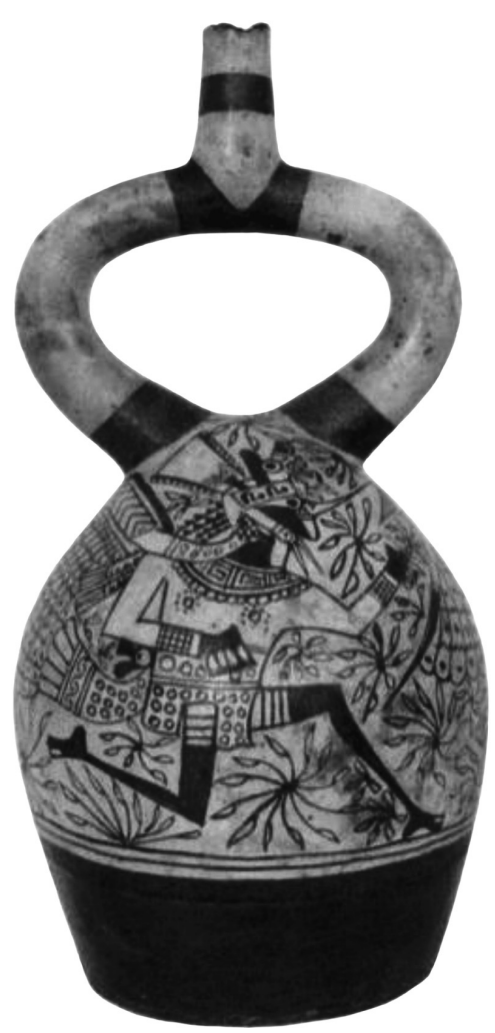




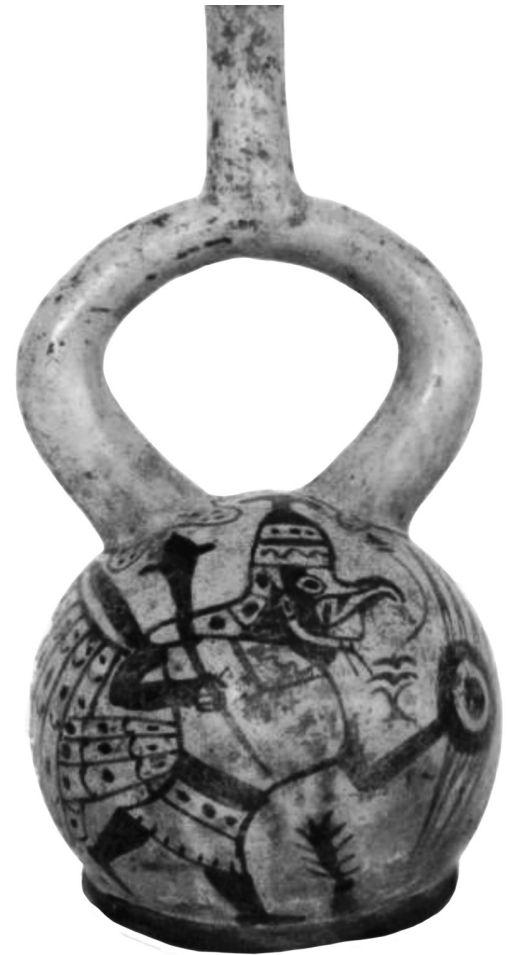

Fig. 7. Representação de "guerreiro ave de rapina". Acervo do Museu de Arqueologia e Etnologia da USP (RG 3573). Fotografia da autora.

Estes combates eram realizados em pares (enfatizando a questão da dualidade), e o guerreiro derrotado seria destituído de suas ricas vestimentas e levado como prisioneiro até o local do sacrifício (Castillo 2000: 3). O guerreiro ave de rapina (apresentado na Figura 7) carrega em suas mãos um arsenal composto por um escudo, uma maça de guerra e algumas armas que lembram dardos, utilizados em batalhas como essa.

Além da batalha ritual, dentre os eventos ligados à questão sacrificial, estaria incluida também uma espécie de "corrida ritual". Em detalhe, na Fig. 6a, é possivel notar que o guerreiro beija-flor carrega em uma das mãos uma pequena bolsa. Bolsas deste tipo estão intimamente ligadas à questão das corridas rituais. Em seu conteúdo, estariam feijões de lima. Estes feijões seriam utilizados no momento final da corrida, quando todos os guerreiros, ao atingirem um determinado local, se sentari- am em pares e fariam uma espécie de "leitura" destes feijões (Arcuri 2009: 44). Cada um dos feijões possuiria marcas diferenciadas. ${ }^{16}$ Talvez esse ato possua um caráter divinatório, assemelhando-se a um "jogo de búzios" (Walter Alva, comunicação pessoal). Na Fig. 8, observam-se imagens de feijões aliados a simbolos escalonados.

A grande quantidade de animais envolvidos nas representações de guerreiros, relacionados a todos os âmbitos (terrestre, aquático e aéreo), exprime a importância dada ao "todo da natureza", ou à "multiplicidade", na composição tanto dos rituais em si (já que esses eram muito provavelmente encenados e cada guerrei-

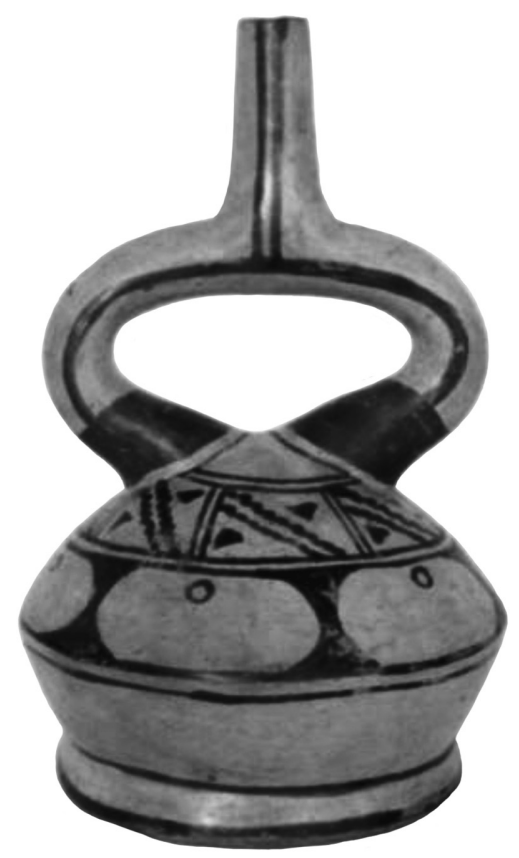

Fig. 8. Sobre o bojo do vaso cerâmico, representações de sememas de "escalonados", no friso superior, e de "feijões de lima", no friso inferior. Acervo do Museu de Arqueologia e Etnologia da USP (RG 3584). Fotografia da autora.

(16) Achados arqueológicos hoje pertencentes ao acervo do Museu Larco confirmam a existência de bolsas deste tipo. Na iconografia mochica, há inúmeras representações destes feijões, cada um com marcas caracteristicas, indicando possiveis valores simbólicos diversos atribuídos a cada um deles. 
ro representaria um animal diferente ${ }^{17}$ ) quanto nas expressões iconográficas. Segundo Alva Meneses (2006: 148), "ao estabelecer paralelismos entre os diferentes reinos animais, a ideologia mochica pode explicar a unidade do cosmos, integrada por niveis inter-relacionados". Como ocorre geralmente no caso mochica, conceitos relacionados à dualidade (como o fato dos guerreiros sempre se enfrentarem em pares nas batalhas) são também representados nas vestimentas e ornamentos dos próprios guerreiros. Na Fig. 9, nota-se que o vaso cerâmico no formato escultórico de um guerreiro antropozoomorfo foi pintado com duas cores diferentes, enfatizando a questão da dualidade não só nas vestimentas, mas no corpo todo do personagem, separandoo em duas "metades" iguais, uma clara, outra escura ${ }^{18} \mathrm{~A}$ dualidade se faz presente também na própria forma de apresentação dos personagens sobre os vasos. Dentre as representações mochicas, é muito comum que um mesmo personagem, ou cena, seja "duplicado" nos dois lados de um mesmo vaso. Por vezes, há modificações minimas entre as representações, mas, de fato, elas sempre apresentam uma espécie de "repetição" do que é visto do outro lado ${ }^{19} \mathrm{Os}$ artefatos vistos nas Figuras 1a e 1b, 6 e 7 apresentam imagens duplicadas, quase idênticas, uma de cada lado do vaso.

(17) É sabido, de acordo com os resultados obtidos com as escavações em Sipán, que alguns guerreiros eram enterrados com toucados e ornamentos ligados a imagens de animais, de forma análoga à iconografia (Walter Alva, comunicação pessoal). Da mesma forma, foram encontrados, em sítios como Sipán e San José de Moro, enterramentos de outros personagens que também, assim como os guerreiros, fazem parte das cenas de sacrificio.

(18) A percepção desta divisão está mais evidente na parte inferior do guerreiro (da cintura para baixo). Ela também ocorre da mesma forma na parte superior, dividindo o guerreiro "ao meio", porém a pintura nesta área está hoje menos evidente. A paleta de cores escolhida para a pintura dos vasos mochicas era limitada. Sua função parece ter sido de fato ressaltar a questão metafórica do "claro" e do "escuro".

(19) A "repetição" ou "duplicação" de temas, representações pictóricas, símbolos ou estruturas é expressada não só através da cultura material como também se faz evidente na distribuição espacial das práticas rituais, conforme apontado por Platt (1978), Moseley (1992) e Rotorowski (1998), entre outros.
Na própria dualidade haveria um movimento, pois os "pares" poderiam ser vistos sob pontos de vista diversos, assumindo diferentes significados. As "modificações mínimas", inseridas em muitas dessas imagens duplicadas, apontam para as diferentes manifestações de um mesmo personagem, de acordo com o contexto no qual poderiam estar inseridos. Em detalhe, na Figura 6a, observam-se símbolos de "volutas" representados de forma geometrizada, na imagem do guerreiro beija-flor, que está duplicada do outro lado do vaso. A presença das volutas enfatiza a questão deste movimento. "A visão dos mochicas (...) é uma sintese estranha de uma ideologia mítica, de uma crença em um mundo em movimento perpétuo e de uma natureza povoada de seres humanos e animais, em luta eterna e em posse de um poder mágico que lhes permite transformar, inteira ou parcialmente, sua aparência, acrescentando a esta transformação suas próprias capacidades, ou adicionando a ela capacidades alheias" (Klein 1967: 60).

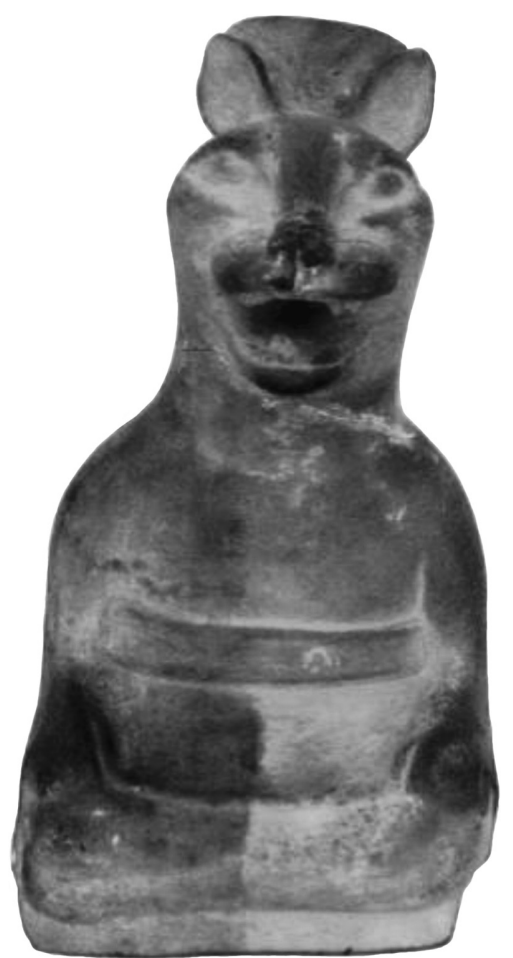

Fig. 9. Representação de "guerreiro antropozoomorfo". Acervo do Museu de Arqueologia e Etnologia da USP (X 715). Fotografia da autora. 
A mescla de elementos presentes na maior parte das imagens de personagens supranaturais, exaltando as questões do movimento dinâmico envolvido nas manifestações de "unicidade", multiplicidade" e "dualidade", pode ser observada não só entre as representações mochicas, mas também na iconografia de diversos povos andinos ao longo do tempo, desde as imagens presentes em artefatos cupisnique às vistas nas feições arquitetônicas de Chavin de Huantar, nos artefatos nasca, paracas, recuay, chimú etc. e, de forma mais sintética e geometrizada, também nos artefatos incas. Esta grande "mescla" traduz o reconhecimento da importância que possuem todas as formas de vida para a manutenção dos ciclos e dos movimentos infindáveis da natureza. Este é um artigo sucinto, que conta com a análise de um número reduzido de artefatos. Entretanto, os conceitos simbólicos expressos por suas imagens traduzem, de forma sintética as estruturas que suportam conceitos de uma cosmovisão que, de certa forma, está presente na produção material de alguns povoados peruanos até hoje.

O método semiótico, bastante útil na verificação de questões ligadas à cosmovisão desses povos, deve ser estendido não só aos artefatos referentes às culturas andinas ou précolombianas. Em realidade, qualquer estudo iconográfico em arqueologia pode se beneficiar desta metodologia, conforme foi extensivamente discutido por Preucel (2006) e demonstrado por Bars (2010). A semiótica permite que seja aberta uma "via de acesso" para a compreensão do funcionamento dos sistemas simbólicos expressos pela produção material de uma sociedade. Seu valor como ferramenta metodológica pode se tornar ainda maior no caso de sociedades sem "escrita", no sentido moderno do termo. Pois, para a semiótica, de certa forma, é possivel "ler" as imagens, até certo ponto, por meio da compreensão da combinação de suas unidades de significação, ou sememas. Este método, que segundo seus principais "criadores" (Saussure e Peirce) teria desde o início o status de ciência, quando utilizado de forma consciente, traduz nos resultados das análises que produz tanto "a objetividade quanto a interpretação"; tanto o rigor científico como os "saltos interpretativos" de Shanks (1999). Segundo Zubrow, os estudos em arqueologia deveriam ser "sinteticamente cientificos e interpretativos" (Zubrow 1994: 107). Esta talvez seja a principal característica de estudos arqueológicos produzidos com base na semiótica.

BARS, C.R. The Mochica Collection of the Museu de Arqueologia e Etnologia of the University of São Paulo: material remains of the Andean cosmology. Revista do Museu de Arqueologia e Etnologia, São Paulo, 20: 345-359, 2010.

Abstract: This article intends to discuss ideas related to the Andean Cosmology through the analysis of the iconography found in artifacts of the Mochica collection of the Museum of Archeology and Ethnology of the University of São Paulo. It is also demonstrated how the semiotics methodology, applied to archeology, becomes an excellent tool for studies that involve artifacts which serve as basis for complex iconographies.

Keywords: Andean cosmology - Mochica iconography - Archaeological semiotics. 


\section{Referências bibliográficas}

ALVA, W.

2006 A escavação das tumbas reais de Sipán. In: ALVA, W. (Ed.) Tesouros do Senhor de Sipán, Peru. O Esplendor da Cultura Mochica. São Paulo: Stilgraf: 19-31

ALVA MENESES, N.I.

2006 As Imagens e os Simbolos da Tumbas de Sipán. In: Alva, W. (Ed.) Tesouros do Senhor de Sipán, Peru. O Esplendor da Cultura Mochica. São Paulo: Stilgraf: 145-157.

ARCURI, M.

2009 O Tahuantinsuyu e o poder das huacas nas relações centro x periferia de Cusco. Revista do Museu de Arqueologia e Etnologia, São Paulo: Suplemento 8: 33-49.

BARS, C. R.

2010 O Felino na Iconografia Mochica: Análise dos Padrões de Estilização na Cerâmica Ritual. Dissertação de Mestrado. Museu de Arqueologia e Etnologia da Universidade de São Paulo, São Paulo.

BOISSAC, P.

2003 Criteria of Symbolicity: Intrinsic and extrinsic formal properties of artifacts. $9^{\text {th }}$ Annual Meeting of the European Archaeologists Associations. Disponivel em www. semioticon.com, acesso em 19/07/2010.

BENSON, E. P.

1972 The Mochica: a culture of Peru. London: Thames \& Hudson.

BOURGET, S.

1994 Bestiaire Sacré et Flore Magique: Écologie Rituelle de Liconographie de la Culture Mochica, Côte Nord du Peru. Tese de Doutorado. Université de MóntrealDepartemant d'Antrhopologie, Faculté des Arts et Sciences, Montreal.

2001 Rituals of Sacrifice: Its Practice at Huaca de la Luna and Its Representation in Moche Iconography. In : PILLSBURY, J. Moche Art and Archaeology in Ancient Peru. Studies in the History of Art. Washington : Center for Advanced Study in the Visual Arts: 89-109.

2006 Sex, Death and Sacrifice in Moche Religion and Visual Culture. Austin : University of Texas Press

BRODA, J.

2001 Introducción. In: Broda, J.; Baéz- Jorge, F. (Eds.) Cosmovisión, Ritual e identidad de los pueblos Indígenas de México. México D.F.: Fondo de Cultura Econômica: 15-45.
CASTILLO. L.J.B.

2000 La Cerimônia del Sacrifício - Batalla y Muerte el Arte Mochica. Material informativo producido para a exposição de mesmo nome: Museu Arqueologico Rafael Larco Herrera, Fevereiro a Agosto de 2000. Lima, 2000.

CHASE, P.G.; DIBBLE, H.L.

1987 Middle Paleolithic Symbolism: a review of current evidence and interpretations. Journal of Anthropological Archaeology, 6: 193-214.

CHASE, P. G.

1991 Symbols and Paleolithic Artifacts. Journal of Anthropological Archaeology, 10: 193 -214.

COELHO, V.P.

1977 A Coleção Max Uhle. São Paulo: Fundo de Pesquisas do Museu Paulista.

CORDY-COLLINS, A.

1992 Archaism or Tradition? The Decaptation Theme in Cupisnique and Moche Iconography. Latin American Antiquity, 3: 206-220.

DONNAN, C.

1976 Moche Art and Iconography. Los Angeles; University of California: Latin American Studies Publications.

DONNAN, C.; MCCLELLAND, D.

1979 The Burial Theme in Moche Iconography. Washington DC: Dumbarton Oaks.

FRANK, M.

1989 What is Neo-Structuralism? Minneapolis: University of Minnesota Press.

GOLTE, J.

2004 Un universo oculto. Baessler-Archiv, 52: 125-174.

2005 La Construcción de la Naturaleza en el Mundo Prehisoanico Andino, su Continuación en el Mundo Colonial y en La Época Moderna. Revista de Antropologia, 3 (3). Universidad Nacional Mayor de San Marcos, Facultad de Ciencias Sociales: 1-43.

2006 Construcción de sentido en una cosmovisión o novela policíaca: la secuencia del entierro en la iconografia. In: XIX Reunión anual de etnología (Anales de la reunión anual de etnología). La Paz: Museo Nacional de Etnografia y Folklore (MUSEF): 757-806.

GREIMAS, A. J.

2004 Semiótica figurativa e semiótica plástica. 
In : Oliveira, A.C. (Org.) Semiótica

Plástica. São Paulo: Hacker Editores: 75-96

HARLAND, R

1987 Superestructuralism: The Philosophy of Structuralism and Post-Structuralism. London: Methuen.

1993 Beyond Superstructuralism: The Syntagmatic Side of Language. London: Routledge.

HARTSHORNE, C.; WEISS, P. (ORGS.)

1931 Collected Writings of Charles Sandres Peirce (8 Vols.). Cambridge: Harvard University Press.

HOCQUENGHEM, A. M.

1983 The "Beauty" of the "Deer Serpent Jaguar". Camak, Beilage 1 Zu Mexicon, Berlin: 4-7.

HODDER, I.

1987 The Archaeology of Contextual Meanings. Cambridge: Cambridge University Press.

HURTADO RODRIGUEZ, L.

2006 Permanência do Fenômeno do Xamanismo. In: Alva, W. (Ed.) Tesouros do Senhor de Sipán, Peru. O Esplendor da Cultura Mochica. São Paulo: Stilgraf: 173-175.

KLEIN, O.

1967 La Ceramica Mochica: Caracteres Estilisticos e Conceptos. Valparaíso: Universidad Técnica Frederico Santa Maria.

KUTSCHER, G.

1954 Cerámica del Peru Septentrional. Berlin: Casa Editora GerMann.

LARCO HOYLE, R.

2001 Los Mochicas. Tomos I e II. Lima: Metrocolor, [1938].

LAVALLÉE, D.

1970 Les Representations Animales dans la Ceramique Mochica. Paris: Institut d'Ethnologie, Musée de l'Homme.

LEMOS, M.T.T.B.

1998 Cosmovisões e Representações Miticas do Incáico. Anais da ANPUH- Associação Nacional de História. Rio de Janeiro. Disponivel em: http://www.rj.anpuh.org /Anais/ 1998/autor/ Maria\% 20Teresa\% 20Toribio\% 20Brittes\% 20Lemos.doc Data de acesso: 13/02/2008.

LOPES, I.C.; HERNANDES, N.

2005 Semiótica - Objetos e Práticas. São Paulo: Contexto.

LUMBRERAS, L.G.

1976 The Peoples and Cultures of Ancient Peru. Washington DC: Smithsonian Institution Press.
MOSELEY, M.E.

1992 The Incas and their Ancestors. The Archaeology of Peru. London: Thames and Hudson.

NOUBLE, W.; DAVIDSON, I.

1996 Human Evolution, Language and Mind: A Psicological and Archaeological Inquiry. Cambridge: Cambridge University Press.

OLIVEIRA, A.C. (Org.)

2004 Semiótica Plástica. São Paulo: Hacker Editores.

PLATT, T.

1978 Symétrie en Mirroir. Le Concept de yanantin chez le Macha de Bolivie Annales, 33, v.5-6 Paris: 1081-1107.

PREUCEL, R.W.

2006 Archaeological Semiotics. Oxford: Blackwell.

RENFREW, C.: BAHN, P.

1991 Archaeology. Theories, Methods and Practice. London: Thames \& Hudson.

ROSTWOROWSKI, M.D.C.

1998 Estructuras Andinas del Poder. Ideología Religiosa y politica. Lima: Instituto de Estudios Peruanos-IEP.

SAUSSURE, F.

1974 Course in General Linguistics. London: Fontana/Collins [1916]

SHANKS, M.

1999 Art and the Early Greek State: An Interpretive Archaeology. Cambridge University Press.

VIVEIROS DE CASTRO, E

2002 A Inconstância da Alma Selvagem e Outros Ensaios de Antropologia. São Paulo: Cosac $\&$ Naify.

WASSÉN, H.S.

1989 El Ulluchu en la Iconografia y Cerimonias de Sangre Moche: la Busqueda desu Identificacion. Boletin del Mus eo Chileno de Arte Pre-colombino, 3, Santiago de Chile: 25-45.

WYNN, T.

1993 Two developments in the mind of early Homo. Journal of Anthropological Archaeology, 12: 299-322.

ZUBROW, E.B.W.

1994 Knowledge Representation and Archaeology: a Cognitive Example Using GIS.In: Renfrew, C.; Zubrow, E.B.W. (Eds.) The Ancient Mind: Elements of Cognitive Archeology. Cambridge: Cambridge University Press: 107-119. 